\title{
ENDOMETRIAL STROMAL CELLS: ISOLATION, EXPANSION, MORPHOLOGICAL AND FUNCTIONAL PROPERTIES
}

\author{
A.V. Zlatska, 2, *, A.E. Rodnichenko ${ }^{1,2}$, O.S. Gubar, , D.O. Zubov ${ }^{1,2}$, S.N. Novikova ${ }^{1}$, R.G. Vasyliev ${ }^{1,2}$ \\ ${ }^{1}$ State Institute of Genetic and Regenerative Medicine of National Academy of Medical Sciences \\ of Ukraine, Kyiv 04114, Ukraine \\ ${ }^{2}$ Biotechnology Laboratory ilaya.regeneration, Medical Company ilaya ${ }^{\circledR}$, Kyiv 03115, Ukraine \\ ${ }^{3}$ Institute of Molecular Biology and Genetics, National Academy of Sciences of Ukraine, Kyiv 03143, Ukraine
}

\begin{abstract}
Aim: We aimed to study biological properties of human endometrial stromal cells in vitro. Materials and Methods: The endometrium samples $(n=5)$ were obtained by biopsy at the first phase of the menstrual cycle from women with endometrial hypoplasia. In all cases, a voluntary written informed consent was obtained from the patients. Endometrial fragments were dissociated by enzymatic treatment. The cells were cultured in DMEM/F12 supplemented with $10 \% \mathrm{FBS}, 2 \mathrm{mM} L$-glutamine and $1 \mathrm{ng} / \mathrm{ml} \mathrm{FGF-2} \mathrm{in} \mathrm{a} \mathrm{multi-gas} \mathrm{incubator}$ at $5 \% \mathrm{CO}_{2}$ and $5 \% \mathrm{O}_{2}$. At P3 the cells were subjected to immunophenotyping, multilineage differentiation, karyotype stability and colony forming efficiency. The cell secretome was assessed by BioRad Multiplex immunoassay kit. Results: Primary population of endometrial cells was heterogeneous and contained cells with fibroblast-like and epithelial-like morphology, but at P3 the majority of cell population had fibroblast-like morphology. The cells possessed typical for $\mathrm{MSCs}$ phenotype $\mathrm{CD}^{+} \mathbf{C D}^{+} \mathbf{C 5}^{+} \mathrm{CD}^{+}{ }^{+} \mathrm{CD} 34-\mathrm{CD} 45-\mathrm{HLA}-\mathrm{DR}$ - The cells also expressed CD140a, CD140b, CD146, and CD166 antigents; and were negative for CD106, CD184, CD271, and CD325. Cell doubling time was $29.6 \pm 1.3 \mathrm{~h}$. The cells were capable of directed osteogenic, adipogenic and chondrogenic differentiation. The cells showed 35.7\% colony forming efficiency and a tendency to 3D spheroid formation. The GTG-banding assay confirmed the stability of eMSC karyotype during long-term culturing (up to P8). After $48 \mathrm{~h}$ incubation period in serum-free medium eMSC secreted anti-inflammatory IL-1ra, as well as IL-6, IL-8 and IFN $\gamma$, angiogenic factors VEGF, GM-CSF and FGF-2, chemokines IP-10 and MCP-1. Conclusion: Thus, cultured endometrial stromal cells meet minimal ISCT criteria for MSC. Proliferative potential, karyotype stability, multilineage plasticity and secretome profile make eMSC an attractive object for the regenerative medicine use.

Key Words: endometrium, mesenchymal stromal cells, secretome, regenerative medicine.
\end{abstract}

The development of cell biology and regenerative medicine methods open up new opportunities for the treatment of a number of pathological conditions, the study of their pathogenesis and the possibilities for correction.

Mesenchymal stem/stromal cells (MSC), the major cell type for cell therapy, have been used in the clinic for approximately 15 years [1]. They are free of ethical concerns and have numerous sources, low immunogenicity and no risk of teratoma formation. For this reasons the MSC are the most commonly used stem cells in current clinical applications. Although MSC for cell therapy have been shown to be safe and effective, there are still challenges that need to be tackled before their wide application in the clinic.

MSC exist in almost all tissues. They can be easily isolated from the bone marrow, adipose tissue, umbilical cord, dental pulp, and extra-embryonic tissues and can be successfully expanded in vitro [2-7].

Submitted: August 08, 2017.

*Correspondence: E-mail: alenazlacka@gmail.com

Tel.: +380978669174

Abbreviations used: eMSC - endometrial mesenchymal stromal cells; FACS - fluorescence-activated cell sorting; FGF-2 - basic fibroblast growth factor; GM-CSF - granulocyte-macrophage colony-stimulating factor; IFNY - interferon gamma; IL-1 ra - interleukin-1 receptor antagonist; IL-6 - interleukin-6; IL-8 - interleukin-8; IP-10 - interferon gamma-induced protein 10; ISCT International Society for Cellular Therapy; MCP-1 - monocyte chemoattractant protein-1; MSC - mesenchymal stromal cells; VEGF - vascular endothelial growth factor.
The endometrium is a unique structure that is able to complete self-renewal over the month cycle, and undergoes these changes over 400 times during woman reproductive age [8]. A significant regenerative potential is due to the presence of stem cells in the endometrium, such as mesenchymal, epithelial and endothelial progenitor cells [9]. The endometrium is a hormone-sensitive structure. For this reason, it is necessary to use tissue-specific MSC for development of cell-based regenerative medicine approaches.

Interest for MSC using in regenerative medicine related not only of their structural integration in damaged or diseased tissues and organs, but also for their trophic effect. So, the study of secretion profile of interleukins (IL), chemokines and growth factors of endometrial mesenchymal stromal cells (eMSC) is important task.

Considering of above mention the endometrium is a promising object for MSC isolation and in vitro large-scale expansion for their further application in reproductology and regenerative medicine.

\section{MATERIALS AND METHODS}

Experiments were done in accordance with the bioethics and biological safety norms confirmed by the Medical Company ilaya ${ }^{\circledR}$ Bioethics Commission permission.

The endometrium samples $(n=5)$ were obtained by biopsy at the first phase of the menstrual cycle from women with endometrial hypoplasia. In all cases, a voluntary written informed consent was obtained from the patients. 
Cell isolation and culturing. Endometrial fragments were dissociated by enzymatic treatment for $1 \mathrm{~h}$ in $0.1 \%$ collagenase $\mathrm{IA}$ and $0.1 \%$ pronase and $2 \%$ FBS. The cells were cultured in DMEM/F12 supplemented with $10 \% \mathrm{FBS}, 2 \mathrm{mM}$ L-glutamine and $1 \mathrm{ng} / \mathrm{ml}$ basic fibroblast growth factor (FGF-2) in a multi-gas incubator at $5 \% \mathrm{CO}_{2}$ and $5 \% \mathrm{O}_{2}$. All reagents were from SigmaAldrich, USA. The P3 cells were used for the phenotype determination, directed adipogenic, osteogenic and chondrogenic differentiation assays, colony forming units test and karyotype stability.

Flow cytometry. The cell phenotype was assessed by fluorescence-activated cell sorting (FACS) on the
BD FACSAria flow cytometer (BD Pharmingen, BD Horizon, USA). Staining with the monoclonal antibodies (PerCP-Cy5.5 mouse anti-human CD105, APC mouse anti-human CD73, FITC mouse anti-human CD90, PECy5 mouse anti-human HLA-DR, APC mouseanti-human CD34, FITC mouse anti-human CD45, PE-CF592 mouse anti-human CD146, BV421 mouse anti-human CD166, PE mouse anti-human CD106, PerCP-Cy5.5 mouse antihuman CD140a, PE-CF592 mouse anti-human CD140b, APC mouse anti-human CD184, PE-CF592 mouse antihuman CD271, FITC mouse anti-human CD325) was performed according to the manufacturer's instructions (BD Pharmingen, BD Horizon, USA).
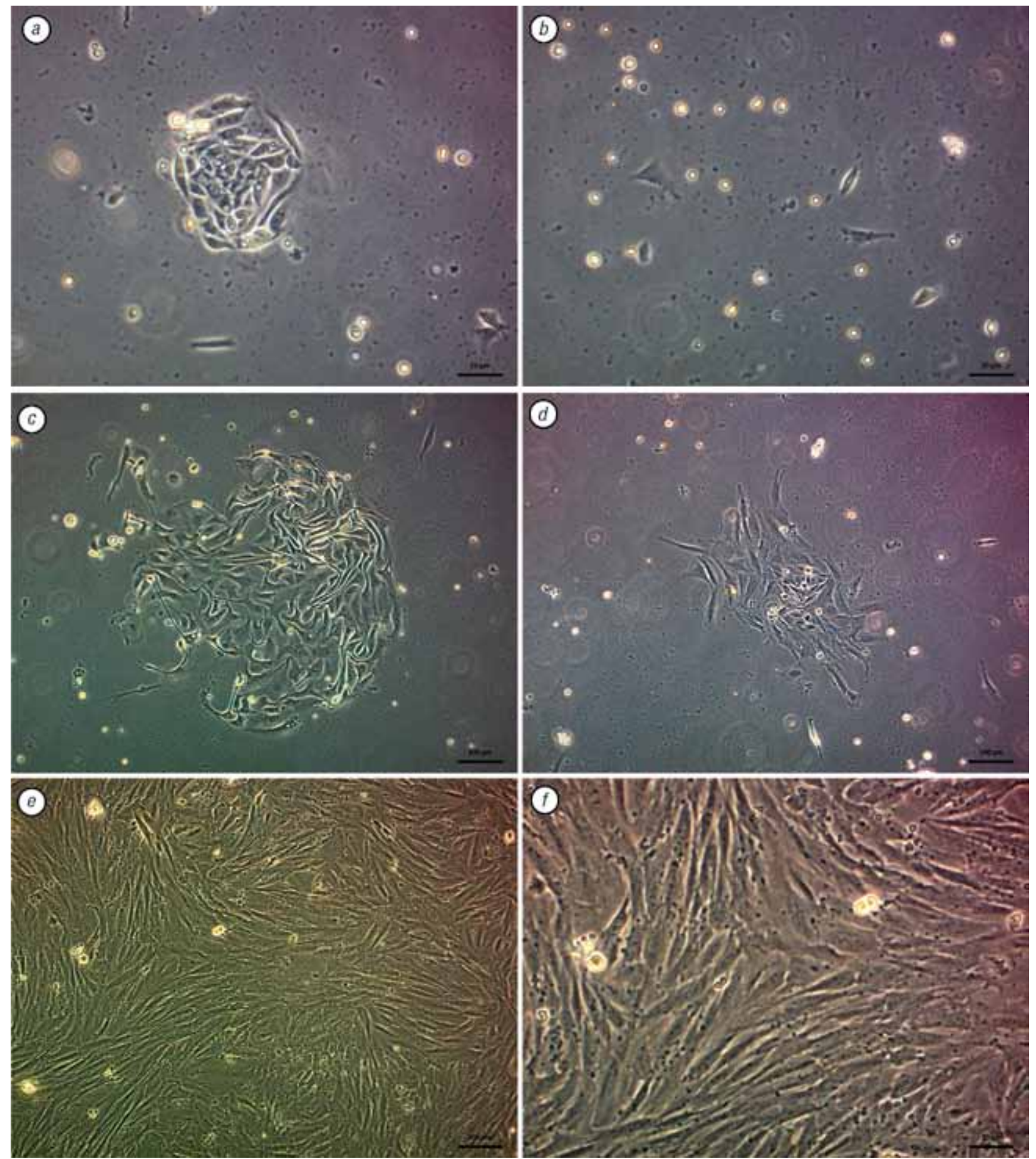

Fig. 1. Morphology of eMSC: $24 \mathrm{~h}$ in culture $(a, b) ; 72 \mathrm{~h}$ in culture $(c, d)$; cell culture at $\mathrm{P} 3(e, f)$. a, $c$ - epiteloid-like morphology; $b, d, e, f$ - fibroblast-like morphology. Phase-contrast microscopy. $a, b, f-$ the bar $=50 \mu \mathrm{m} ; c, d, e-$ the bar $=100 \mu \mathrm{m}$ 
The cell secretome was assessed by BioRad Multiplex immunoassay kit according to manufacturer's instructions.

Directed multilineage differentiation. Adipogenic differentiation was performed in DMEM with high glucose content $(4.5 \mathrm{~g} / \mathrm{l})$ (Sigma-Aldrich, USA) supplemented with $5 \%$ horse serum (PAA, Austria), 10\%
FBS, $1 \mu \mathrm{M}$ dexamethasone, $200 \mu \mathrm{M}$ indomethacine, $500 \mu \mathrm{M}$ isobutylmethylxanthine and $5 \mu \mathrm{g} / \mathrm{ml}$ insulin (all from Sigma-Aldrich, USA). After 14 days the cells were fixed and stained with Oil Red O (Sigma-Aldrich, USA).

Osteogenic differentiation was performed in DMEM with low glucose content $(1 \mathrm{~g} / \mathrm{l})$ with $10 \%$ FBS, $100 \mathrm{nM}$ dexamethasone, $10 \mathrm{mM} \beta$-glycerophosphate
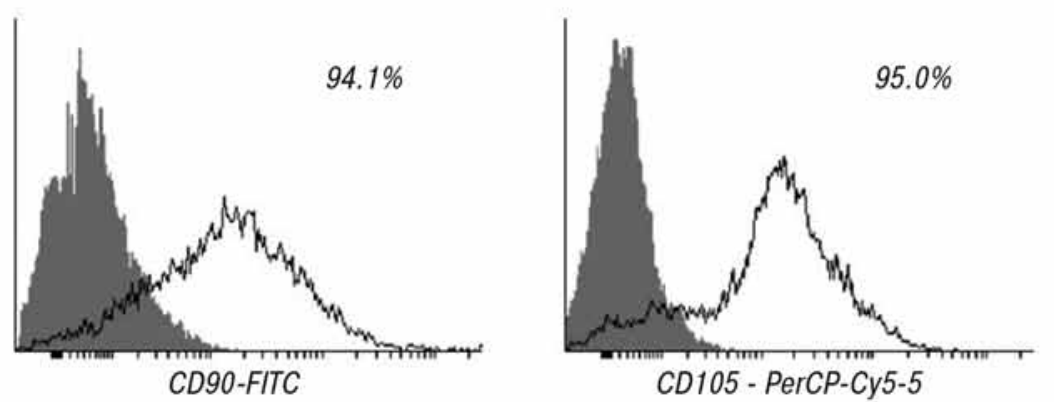
CD105 - PerCP-Cy5-5

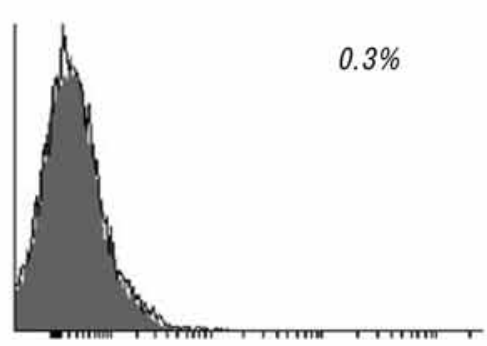

HLA-DR - PE-Cy 5
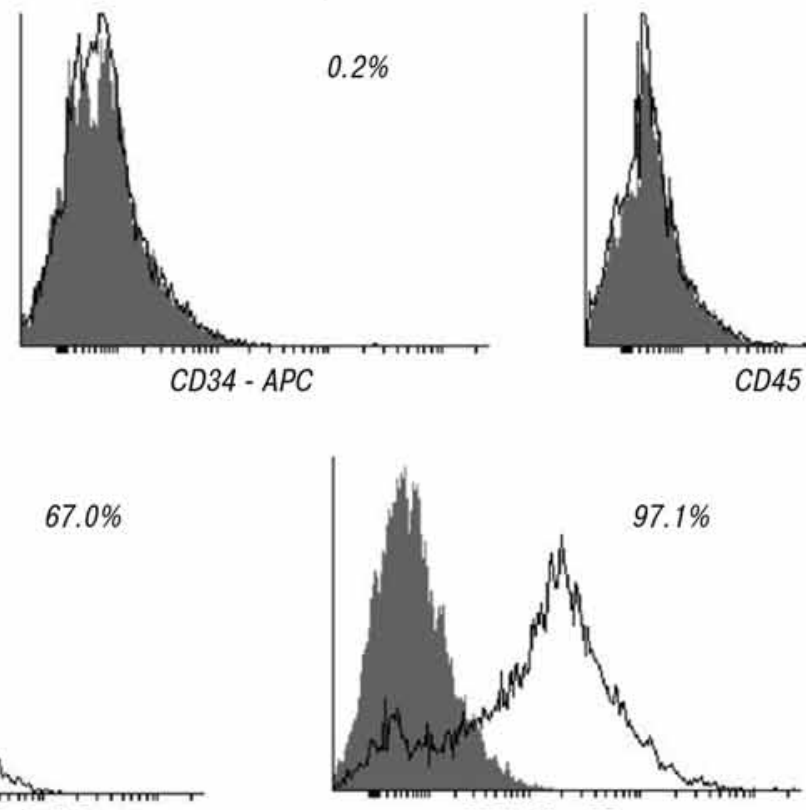

CD140b-PE
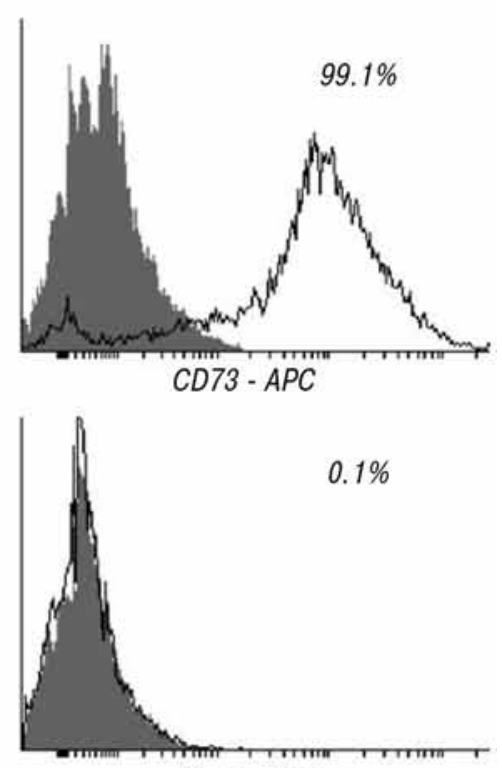

CD45 - FITC

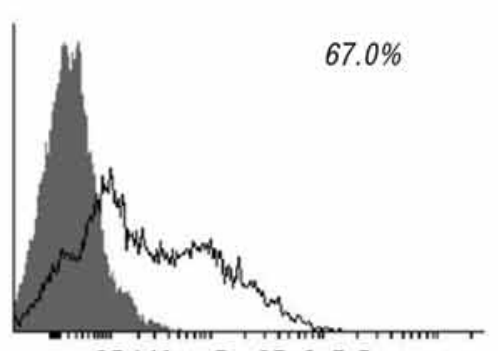

CD140a - PerCP-Cy5-5

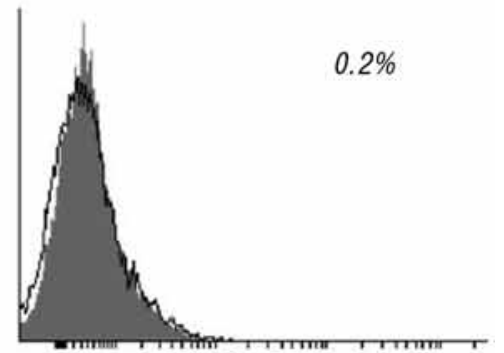

CD106-PE

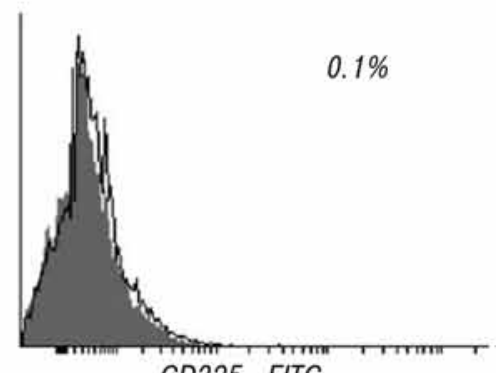

CD325 - FITC

Fig. 2. Representative FACS graphics

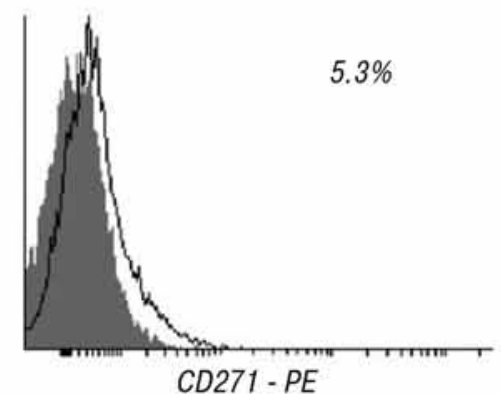




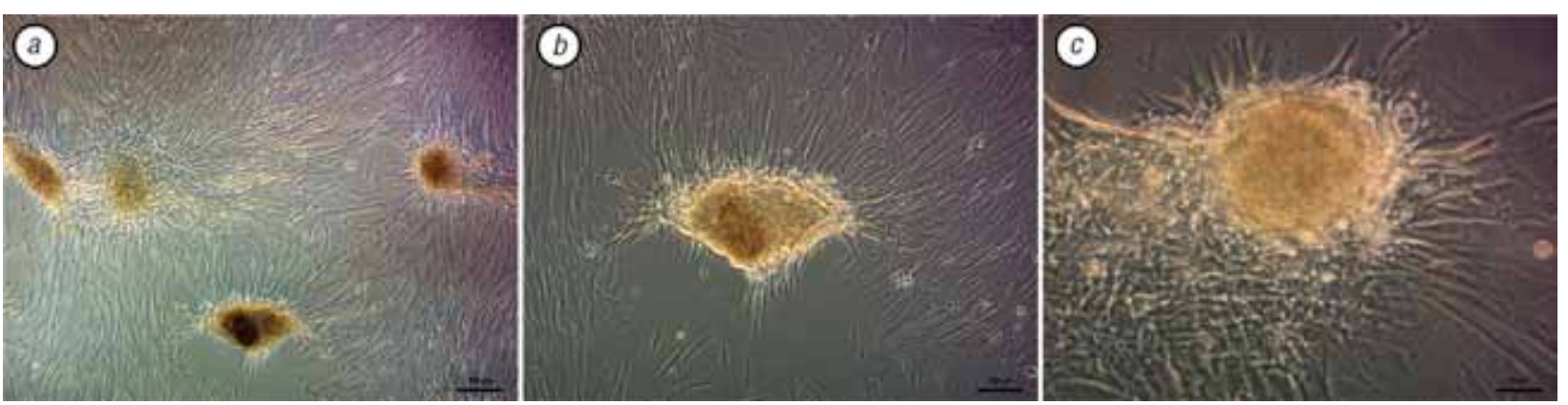

Fig. 3. eMSC 3D-spheroid formation. Phase-contrast microscopy. The bar $=200 \mu \mathrm{m}(a)$; the bar $=10 \mu \mathrm{m}(b)$; the bar $=50 \mu \mathrm{m}(c)$

and $50 \mu \mathrm{g} / \mathrm{ml}$ ascorbate-2-phosphate (all from SigmaAldrich, USA). After 21 days the cells were fixed and stained with Alizarin Red S (Sigma-Aldrich, USA).

Chondrogenic differentiation of cultures was carried out using the micromass culture method, 300,000 cells were centrifuged for $14 \mathrm{~min}$ at $2000 \mathrm{rpm}$ to obtain a precipitate in $15-\mathrm{ml}$ tubes (Nunc, USA). Further the cell pellets were cultured in chondrogenic inductive medium containing DMEM with $4.5 \mathrm{~g} / \mathrm{l}$ glucose (PAA, Germany) with addition of $50 \mu \mathrm{g} / \mathrm{ml}$ ascorbate2-phosphate (Sigma-Aldrich, USA), $40 \mu \mathrm{g} / \mathrm{ml} \mathrm{L-proline}$ (Sigma-Aldrich, USA), $100 \mu \mathrm{g} / \mathrm{ml}$ sodium pyruvate (Sigma-Aldrich, USA), $10 \mathrm{ng} / \mathrm{ml}$ rhTGF- $\beta 3$ (Sigma, USA), 10-7 M dexamethasone (Sigma-Aldrich, USA), 1\% ITS containing $6.25 \mu \mathrm{g} / \mathrm{ml}$ insulin, $6.25 \mu \mathrm{g} / \mathrm{ml}$ transferrin,
$6.25 \mathrm{ng} / \mathrm{ml}$ selenic acid (Gibco, USA), $1.25 \mathrm{mg} / \mathrm{ml}$ bovine serum albumin (Sigma-Aldrich, USA).

Colony forming units test. 100 cells were seeded per $100 \mathrm{mM}$ cell culture dish and cultured for two weeks in standard culture medium with $20 \%$ FBS without medium change. The colonies were fixed with cold $96 \%$ ethanol and stained by Romanowsky.

GTG-banding was performed as decribed previously [10].

The population doubling time was calculated at http://www.doubling-time.com/compute.php [11].

\section{RESULTS AND DISCUSSION}

eMSC primary population morphology. We have obtained five eMSC cultures from five donors $34.0 \pm$ 3.3 years old. One of the characteristics of the MSC


(a)

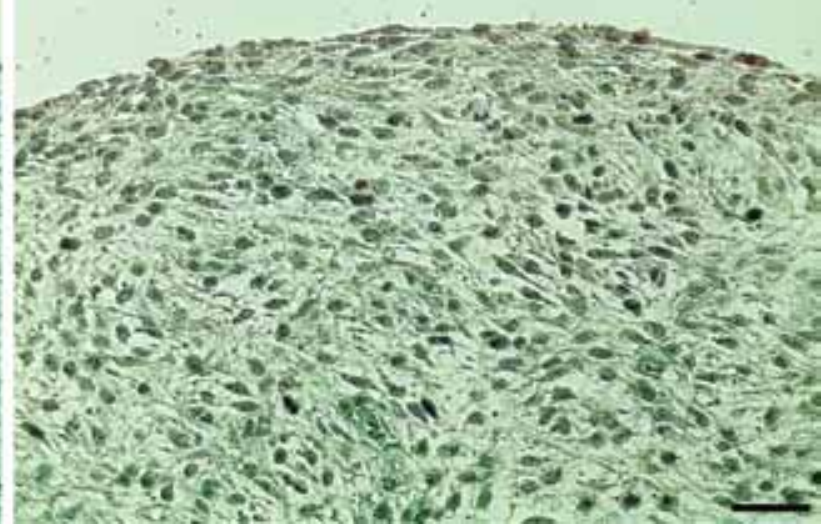

Fig. 4. Multilineage differentiation of eMSC. $a$ - adipogenic differentiation. Red Oil O (red) and Romanowsky (violet) stain. Light microscopy. The bar $=50 \mu \mathrm{m} ; b-$ osteogenic differentiation. Alizarin Red S (red) stain. Light microscopy. The bar $=200 \mu \mathrm{m} . c, d-$ chondrogenic differentiation. Light microscopy. The bar $=200 \mu \mathrm{m} . c$ - Alcian Blue stain (blue), $d$ - Goldner stain (black) 
is their ability to adhere to plastic under standard culture conditions. After $24 \mathrm{~h}$ in culture the cells began to adhere to the plastic. The resulting cell population had a heterogeneous morphology (Fig. 1, $a, b$ ).

After $48 \mathrm{~h}$ of culture, part of the cells began to migrate from non-dissociated conglomerates, forming colonies of small round cells with epithelial-like morphology. There were also single cells with typical fibroblast-like morphology. Further these cells with fibroblast-like morphology actively multiplied and formed colonies, whereas in epithelial-like colonies part of the cells died after $72 \mathrm{~h}$ in culture (Fig. 1, $c, d$ ).

At first two passages, population of eMSC remained heterogeneous and consisted of fibroblastlike and epithelial-like cells which is consistent with previous reports $[8,9]$.

However, at P3 the cell population became rather homogeneous: the majority of cells had fibroblast-like morphology, actively proliferated and formed a monolayer (Fig. 1, e, f).

eMSC immunophenotype. The results of the cell immunophenotyping at $\mathrm{P} 3$ are presented in Table 1 with representative histograms at Fig. 2. eMSC demonstrated high levels of MSC markers expression, e.g. CD73, CD90, CD105, CD90; and did not express markers of hematopoietic progenitor cells, e.g. CD34, CD45, HLA-DR. Positive expression of $\mathrm{CD} 146^{+} \mathrm{CD} 166^{+} \mathrm{CD} 140 \mathrm{a}^{+} \mathrm{CD} 140 \mathrm{~b}^{+}$was also studied. eMSC did not express CD106, CD184, CD271, CD325.

Table 1. Flow cytometry results of eMSC surface antigen expression (data presented as a percentage of parent population from 5 donors)

\begin{tabular}{ccccccc}
\hline Antigens & № 1 & № 2 & № 3 & № 4 & № 5 & Mean \pm SD \\
\hline CD105 & 93.2 & 93.7 & 95.3 & 95 & 95.4 & $94.5 \pm 1.0$ \\
CD73 & 95.4 & 98.9 & 99.2 & 99.1 & 97.9 & $98.1 \pm 1.6$ \\
CD90 & 84.0 & 95.9 & 94.7 & 93.1 & 93.3 & $92.2 \pm 4.7$ \\
CD34 & 0.1 & 0.3 & 0.3 & 0.2 & 0.2 & $0.2 \pm 0.1$ \\
CD45 & 0.2 & 0.3 & 0.3 & 0.1 & 0.3 & $0.2 \pm 0.9$ \\
HLA-DR & 0.7 & 0.3 & 0.5 & 0.8 & 0.3 & $0.5 \pm 0.2$ \\
CD140a & 67.5 & 66.8 & 61.2 & 67.0 & 86.7 & $69.8 \pm 9.7$ \\
CD140b & 96.9 & 92.7 & 94.8 & 92.9 & 97.1 & $94.9 \pm 2.1$ \\
CD146 & 85.2 & 78.6 & 94.7 & 75.1 & 83.1 & $83.4 \pm 7.5$ \\
CD166 & 87.9 & 77.1 & 88.6 & 82.1 & 79.3 & $83.0 \pm 5.1$ \\
CD106 & 0.3 & 0.6 & 0.3 & 0.2 & 0.3 & $0.35 \pm 0.2$ \\
CD184 & 0.9 & 1.5 & 1.7 & 1.8 & 2.1 & $1.6 \pm 0.4$ \\
CD271 & 6.4 & 4.2 & 5.1 & 5.3 & 6.9 & $5.58 \pm 1.1$ \\
CD325 & 0.1 & 0.2 & 0.1 & 0.15 & 0.2 & $0.14 \pm 0.1$ \\
\hline
\end{tabular}

Colony forming units efficiency and 3D spheroid formation of eMSC. The colony-forming units assay was also performed at P3. All cultures showed $35.7 \pm 2.3 \%$ colony forming efficiency. Moreover, when seeded at high density and cultured for a long time without splitting, all eMSC cell cultures demonstrated a tendency to 3D spheroid formation (Fig. 3).

Directed multilineage differentiation of eMSC. In accordance with the minimal criteria of the International Society for Cellular Therapy (ISCT) [12], multipotency is a mandatory property of any MSC and is determined by their ability for directed in vitro differentiation into mesenchymal derived cell types (adipocytes, osteoblasts and chondrocytes).

All eMSC cultures successfully underwent adipogenic differentiation (Fig. 4, a). However, it was noncanonic (comparing to bone marrow MSC where fat vacuoles are significantly larger and evenly distributed

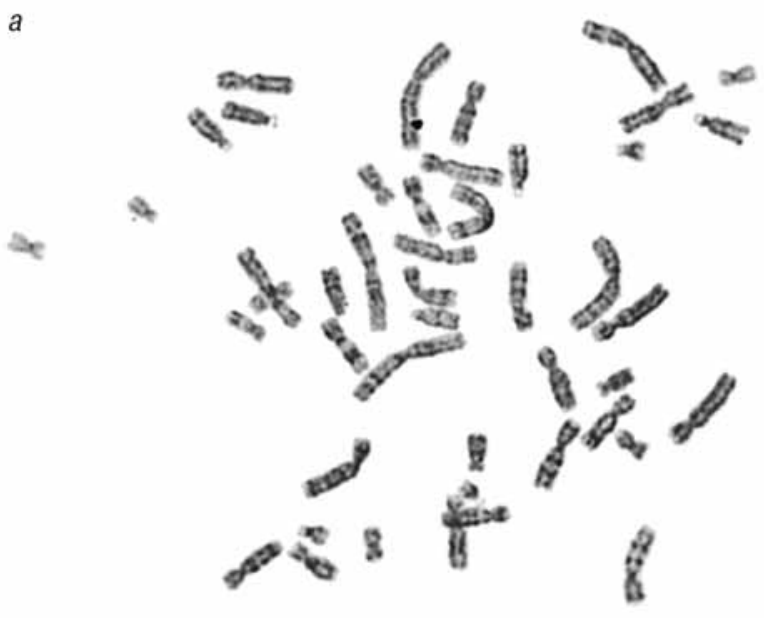

$b$
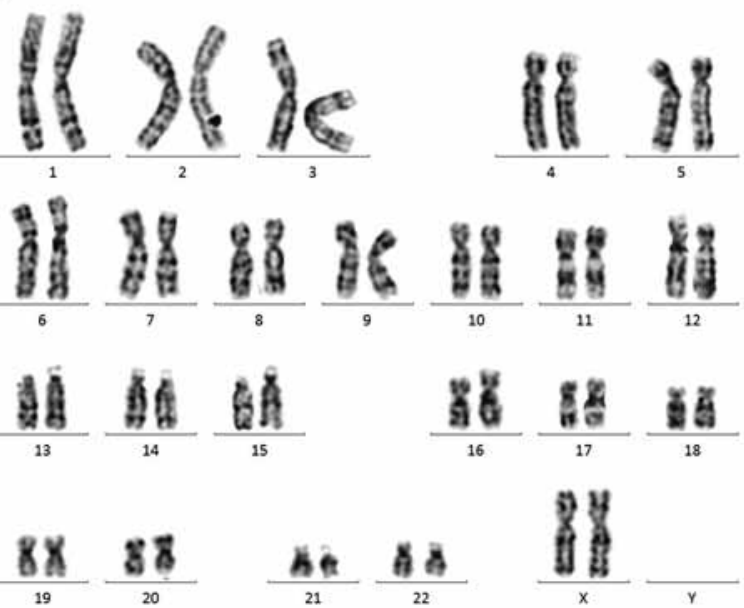

Fig. 5. Representative eMSC karyotype at P8: metaphase plate $(a)$, karyogram $(b)$. Normal female $46, X X$ karyotype

throughout the cytoplasm of the cell) as there were plenty tiny lipid vacuoles located in the perinuclear region.

The eMSC cell culturealso showed positive osteogenic differentiation with the production of $\mathrm{Ca}^{2+}$-mineralized extracellular matrix beginning from the day 14 of induction and with a high-density matrix at day 21 (Fig. 4, b).

The chondrogenic differentiation was also successful with a dense chondroid formation at day 21 of induction (Fig. 4, $c, d$ ).

eMSC secretome. After $48 \mathrm{~h}$ incubation period in serum-free medium eMSC secreted anti-inflammatory IL$1 \mathrm{ra}(74.6 \pm 9.5 \mathrm{pg} / \mathrm{ml})$, as well as IL-6 $(29.8 \pm 8.3 \mathrm{pg} / \mathrm{ml})$, IL-8 (138.5 $\pm 33.3 \mathrm{pg} / \mathrm{ml}$ ) and interferon gamma (IFNy) $(55.9 \pm 3.8 \mathrm{pg} / \mathrm{ml})$, angiogenic factors, vascular endothelial growth factor (VEGF) $(92.2 \pm 19.8 \mathrm{pg} / \mathrm{ml})$, granulocyte-macrophage colony-stimulating factor (GM-CSF) $(133.2 \pm 5.1 \mathrm{pg} / \mathrm{ml})$ and FGF-2 (17.8 $\pm 4.3 \mathrm{pg} / \mathrm{ml})$, chemokines interferon gamma-induced protein 10 (IP-10) $(39.9 \pm 3.3 \mathrm{pg} / \mathrm{ml})$ and monocyte chemoattractant protein-1 (MCP-1) (41.1 $\pm 6.7 \mathrm{pg} / \mathrm{ml})$ (Table 2).

Karyotype stability and cell doubling time of eMSC. Cell doubling time at P3 was in average $29.6 \pm 1.3 \mathrm{~h}$ for all five cell cultures. Moreover, eMSC maintained stable karyotype during long-term culturing up to P8 (Fig. 5). Altogether these data indicate a high proliferation rate and genetic stability of eMSC. 
Table 2. Levels of cytokines and growth factors production of eMSC

\begin{tabular}{lcc}
\hline Cytokines & IL-1ra, pg/ml & $74.6 \pm 9.5$ \\
& IL-6, pg/ml & $29.8 \pm 8.3$ \\
& IL-8, pg/ml & $138.5 \pm 33.3$ \\
Growth factors & IFN, $\mathrm{pg} / \mathrm{ml}$ & $55.9 \pm 3.8$ \\
& VEGF, pg/ml & $92.2 \pm 19.8$ \\
& GM-CSF, pg/ml & $133.2 \pm 5.1$ \\
Chemokines & $\mathrm{FGF}-2, \mathrm{pg} / \mathrm{ml}$ & $17.8 \pm 4.3$ \\
& $\mathrm{IP}-10, \mathrm{pg} / \mathrm{ml}$ & $39.9 \pm 3.3$ \\
& $\mathrm{MCP}-1, \mathrm{pg} / \mathrm{ml}$ & $41.1 \pm 6.7$ \\
\hline
\end{tabular}

Thus, obtained eMSC meet minimal ISCT criteria for MSCs, such as adherence to plastic in standard culture conditions, expression of typical phenotype markers and ability for the directed differentiation in vitro. eMSC are stable during long-term culturing. They also produce a range of cytokines, chemokines and growth factors. Proliferative potential, karyotype stability and secretome profile make them a perspective object for the use for the regenerative medicine application.

\section{REFERENCES}

1. Bianco P, Robey PG, Simmons PJ. Mesenchymal stem cells: revisiting history, concepts, and assays. Cell Stem Cell 2008; 2 : 313-9.

2. Gnecchi M1, Melo LG. Bone marrow-derived mesenchymal stem cells: isolation, expansion, characterization, viral transduction, and production of conditioned medium. Methods Mol Biol 2009; 482: 281-94.
3. Dhanasekaran M, Indumathi S, Poojitha R, et al. Plasticity and banking potential of cultured adipose tissue derived mesenchymal stem cells. Cell Tissue Bank 2013; 14: 303-15.

4. Romanov YA, Svintsitskaya VA, Smirnov VN. Searching for alternative sources of postnatal human mesenchymal stem cells: candidate MSC-like cells from umbilical cord. Stem Cells 2003; 21: 105-10.

5. Karaöz E, Doğan BN, Aksoy A, et al. Isolation and in vitro characterisation of dental pulp stem cells from natal teeth. Histochem Cell Biol 2010; 133: 95-112.

6. Anker PS, Scherjon SA, Kleijburg-van der Keur C, et al. Isolation of mesenchymal stem cells of fetal or maternal origin from human placenta. Stem Cells 2004; 22: 1338-45.

7. Fukuchi Y, Nakajima H, Sugiyama D, et al. Human placenta-derived cells have mesenchymal stem/progenitor cell potential. Stem Cells 2004; 22: 649-58.

8. Gargett C. Stem cells in gynaecology. Austral New Zealand J Obstet Gynaecol 2004; 44: 380-6.

9. Gargett C. Identification and characterization of human endometrial stem/progenitor cells. Austral New Zealand J Obstet Gynaecol 2006; 46: 250-3.

10. Fayazi M, Salehnia M, Ziaei S. The effect of stem cell factor on proliferation of human endometrial CD146+ cells. Int J Reprod Biomed 2016; 14: 437-42.

11. Roth V. 2006 Doubling Time Computing. Available from: http://www.doubling-time.com/compute.php.

12. Dominici $M$, Le Blanc $K$, Mueller I, et al. Minimal criteria for defining multipotent mesenchymal stromal cells. Int Soc Cell Ther Cytother 2006; 8: 315-7. 